\title{
Ecotoxicity Potentials of Residual Paracetamol and Personal Care Products (PPCPS) in Household Waste at the University of Port Harcourt, Nigeria
}

Babatunde $\mathrm{BB}^{1 *}$, Kika PE${ }^{1}$, Ugoeze $\mathrm{KC}^{2}$, Nwanchukwu ${ }^{2}$, Sikoki FD ${ }^{1}$ and Udeala OK ${ }^{2}$

${ }^{1}$ Department of Animal and Environmental Biology, University of Port Harcourt, Port Harcourt, Nigeria

${ }^{2}$ Faculty of Pharmaceutical Sciences, Department of Pharmaceutics and Pharmaceutical Technology, University of Port Harcourt, Port Harcourt, Nigeria

\begin{abstract}
This study evaluated the relative amount of Pharmaceutical and Personal Care Products (PPCPs) and paracetamol residues contained in household waste at the University of Port Harcourt, Port Harcourt, Nigeria. Residual paracetamol was analysed using a 6405 UV/Vis Spectrophotometer at the maximum wavelength $(245 \mathrm{~nm})$ in $0.1 \mathrm{~N} \mathrm{HCL}$. Student hostels had a mean paracetamol concentration of $0.6702 \pm 0.006 \mathrm{mg} / \mathrm{kg}$ while the staff quarters recorded a mean concentration of $0.6569 \pm 0.002 \mathrm{mg} / \mathrm{kg}$. Solid waste analysis recorded $0.9 \mathrm{~kg} / \mathrm{capita} /$ day and $1.1 \mathrm{~kg} / \mathrm{capita} / \mathrm{day}$ for the student hostel and staff quarters respectively. The student's hostel recorded a mean percentage PPCPs value of $52.9 \%$ which was higher than that obtained in the staff quarters (45.9\%) indicating that students disposed of more drugs in their waste than does the staff. The study showed that considerable amounts of PPCPs are disposed of in household waste at the study location and household waste is thus a viable pathway of PPCPs into the environment. Such practices could lead to the occurrence of the active ingredients of PPCPs in the environment with the potential to contaminate surface and ground water posing serious risk to human and ecologic health. It was recommended that appropriate return channels be established specially as a route for disposing of unused or expired drugs. Such routes should encourage stewardship of drugs by manufacturers from cradle to grave in an integrated green pharmacy approach.
\end{abstract}

Keywords: Household waste; Pharmaceuticals and personal care products (PPCPs); Residual paracetamol

\section{Introduction}

Pharmaceuticals and Personal Care Products (PPCPs) are produced and used in increasingly large amount each year wherever man lives. Concerns about the fate and effects of these compounds in the environment have become topical among the scientific community. As opposed to the priority pollutants whose discharge into the environment are now more surreptitious due to regulatory activities PPCPs have enjoyed and are still enjoying unlimited and unregulated discharge into the environment with little knowledge of their potential harm to human and ecological health. This has warranted that detailed investigations be carried out on these contaminants using paradigm methodologies by scientists from different disciplines. Results from such investigations will reveal possible trends in occurrence, fate, exposure and potential physiological effects on ecological and human health. More available data can then form the basis for regulatory or policy decisions on this emerging environmental problem. Moreover, early identification and investigation of a potential environmental problem before it worsens is critical to protecting human and ecological health and also necessary to determine whether the issue is of concern or not so that limited resources can be redirected to other more pressing issues [1].

PPCPs comprise animal and human medicines, diagnostic agents, neutraceuticals, antibiotics, aphrodisiacs sexual enhancement drugs and personal care products such as cosmetics, fragrances, detergents, feminine sanitary products, disinfectants, insect repellants [2]. Their sources include human activity, residues from pharmaceutical manufacturing, residues from hospitals, illicit drugs such as cocaine and methamphetamine, veterinary drug use especially antibiotics and steroids, agro-allied business etc. [1]. Their discovery in environmental samples especially in Europe and America has given rise to concerns over their pathways into the environment and the extent of environmental occurrence, transport, fate and possible physiologic effects on ecological and human health. Comprehensive literature on this emerging environmental problem is still limited. Data available is mostly from Europe and America where PPCPs have been reported to occur at very low levels parts per trillion and parts per billion (ppt and $\mathrm{ppb}$ ) in various environmental media such as soils [3,4], biosolids [5], surface waters, under-ground water and even drinking water [5-9], landfill leachates [10-12] and household waste [13]. PPCPs are said to have high affinity for sediments in which PPCPs were recovered about $50 \%$ more in sediments than in the overlaying surface water $[14,15]$.

The primary source and pathways of PPCPs into the environment stems from their use and disposal by people all over the world and household waste constitute one of the primary routes for domestic disposal of PPCPs [13]. What is more worrisome is people are yet to accept the fact that chemical pollution can occur from consumption actions of individuals [16]. As a result, household chemicals (e.g., detergents, deodorizers, degreasers, disinfectants etc.), pharmaceuticals (e.g., caffeine, hormones, steroids, antibiotics, etc.) and other personal care products (PCPs) (e.g., fragrances and cosmetics) are used in large quantities and washed, excreted and flushed down sinks and toilets and their packaging materials disposed along household waste without a second thought. It has been reported that between 50 to $90 \%$ of some

*Corresponding author: Babatunde BB, Department of Animal and Environmental Biology, University of Port Harcourt, Port Harcourt, Nigeria, Tel: +2348060755192; E-mail: bolaji.babatunde@uniport.edu.ng

Received October 20, 2015; Accepted November 27, 2015; Published November 30,2015

Citation: Babatunde BB, Kika PE, Ugoeze KC, Nwanchukwu N, Sikoki FD et al (2016) Ecotoxicity Potentials of Residual Paracetamol and Personal Care Products (PPCPS) in Household Waste at the University of Port Harcourt, Nigeria. J Environ Anal Toxicol 5: 339. doi:10.4172/2161-0525.1000339

Copyright: (C) 2016 Babatunde BB, et al. This is an open-access article distributed under the terms of the Creative Commons Attribution License, which permits unrestricted use, distribution, and reproduction in any medium, provided the original author and source are credited. 
Citation: Babatunde BB, Kika PE, Ugoeze KC, Nwanchukwu N, Sikoki FD et al. (2016) Ecotoxicity Potentials of Residual Paracetamol and Personal Care Products (PPCPS) in Household Waste at the University of Port Harcourt, Nigeria. J Environ Anal Toxicol 5: 339. doi:10.4172/21610525.1000339

drugs ingested are excreted as its active compound or as a conjugate metabolite into the toilets or directly into water ways as practice in most poor nations like Nigeria [13]. In developed nations, consumers are encouraged to return expired drugs or unused drugs to pharmacies or flushed them down the toilet.

A wide range of pharmaceuticals has been found in fresh and marine waters, and it has recently been shown that even in small quantities, some of these compounds have the potential to cause harm to aquatic life. The primary pathway into the environment is the use and disposal of medicines; although much of the research in this area currently focuses on the removal of pharmaceuticals during sewage treatment processes, disposal via household waste might be a significant pathway requiring further research. It has been demonstrated that disposal of unused pharmaceuticals, either by household waste or via the sink or toilet, may be a prominent route that requires greater attention [13]. The present research investigated the relative composition of PPCPs and residual paracetamol in household waste in two locations at the University of Port Harcourt, Nigeria to determine if household waste is a significant pathway of PPCPs into the environment.

\section{Materials and Methods}

\section{Study Area}

The investigation was carried out at University of Port Harcourt, Nigerian in Rivers State between these coordinate $4^{\circ} 54^{\prime} 01^{\prime \prime} \mathrm{N}$, $6^{\circ} 55^{\prime} 30^{\prime \prime}$, Figure 1 . This study was carried out in one of the university staff quarters (Gambia-ama) and Block D of the female hostel (Delta Park) in University of Port Harcourt which has five wings (A-F). These Locations were chosen because they represent typical urban dwelling in Nigeria, reflecting government quarters and hostel accommodation. Ten houses of the staff quarters were randomly sampled to reduce bias and also the female hostel of the University was surveyed to determine their possible contribution of PPCPs into the environment.

\section{Collection and sorting of samples}

This study was carried out in one of the University staff quarters (Gambia-Ama) and Block D of the female hostel (Delta Park) in the University of Port Harcourt which has five wings (A-F). These Locations were chosen because they represent typical urban dwelling in Nigeria, reflecting government quarters and hostel accommodation. Houses were numbered and ten houses of the staff quarters were randomly sampled to reduce bias and also the female hostel of the University was surveyed to determine their possible contribution of PPCPs especially paracetamol into the environment. Bags for perishable and nonperishable wastes were distributed to the randomly selected houses and the hostel weekly for one month for the disposal of their wastes. These bags were retrieved weekly, weighed and sorted manually according to ASTM D5231-92 (2008) standard method which involves thamol'e direct sampling of solid waste from specific sources. Household wastes were sorted out into two different categories of solid waste and PPCPs. The PPCPs were weighed again to determine its composition in the solid waste and the paracetamol sachets found were taken to the laboratory where they were analyzed to determine the amount of active ingredient left in them.

\section{Preparation of standard curve for paracetamol}

A $50 \mathrm{mg}$ quantity of standard paracetamol was dissolved in about $10 \mathrm{ml}$ of absolute alcohol (Sigma, USA Analytical grade) and made up to $50 \mathrm{ml}$ using $0.1 \mathrm{~N} \mathrm{HCL}$ (Analytical grade Hydrochloric acid) to give a $100 \mathrm{mg}$ stock solution $(1 \mathrm{mg} / \mathrm{ml})$. From this stock solution, aliquots of
0.1-0.5 $\mathrm{ml}$ were measured and each made up to $50 \mathrm{ml}$ using $0.1 \mathrm{~N} \mathrm{HCL}$. Their respective absorbances were determined at $245 \mathrm{~nm}$ using a 6405 UV/Vis spectrophotometer (Jenway, USA). Beer-Lambert's Plot was constructed using Absorbance against concentration of the standard paracetamol sample to obtain an equation which was used to compare values obtained from the samples.

\section{Determination of paracetamol content in samples}

Aliquots of $95 \%$ ethanol were used to wash off the paracetamol from the sachets. Intact tablets were pulverized, dissolved in ethanol and filtered to remove other impurities. The entire dissolutions were made up to $100 \mathrm{ml}$ using ethanol. A $5 \mathrm{ml}$ volume collected from the stock solution of sample dissolutions was made up to $100 \mathrm{ml}$ using 0.1 $\mathrm{N} \mathrm{HCl}$. The content of paracetamol in this solution was determined by a $6405 \mathrm{UV} / \mathrm{Vis}$ spectrophotometer (Jenway, USA) at $245 \mathrm{~nm}$ wavelength (Figure 1).

\section{Results}

\section{Solid waste generated per capita}

The quantity of solid waste generated in the staff quarters and student's hostel is presented in Figures 2 and 3 respectively. The mean quantity of waste generated ranged from $2.775 \mathrm{~kg} /$ day in house 2 to $8.550 \mathrm{~kg} /$ day in house 8 in staff quarters and from $3.075 \mathrm{~kg}$ in wing A to $3.975 \mathrm{~kg}$ in wing $\mathrm{F}$ in the student hostels. House 8 generated the highest average quantity of waste in weeks one two and three respectively while house three recorded the highest in week four. House 2 recorded the least quantity of waste in weeks one and four, house 3 recorded the least in week three while house four recorded the least quantity of waste in week two Figure 2. In the female hostel, wing $\mathrm{C}$ recorded the highest quantity of waste in week one, wing $\mathrm{F}$ recorded the highest in week two and four while wing $\mathrm{E}$ recorded the highest quantity of waste in week three Figure 3.

\section{Relative amounts of PPCPs in staff quarters and students hostel}

The percentage composition of PPCPs in the waste from the staff quarters and students hostel is presented in Figures 4 and 5 respectively. The percentage PPCPs in the waste from the staff quarters ranged from $38.94 \%$ in house 6 to $52.26 \%$ in house 1 while that of student's hostel ranged from $39.69 \%$ in wing A to $65.29 \%$ in wing C.

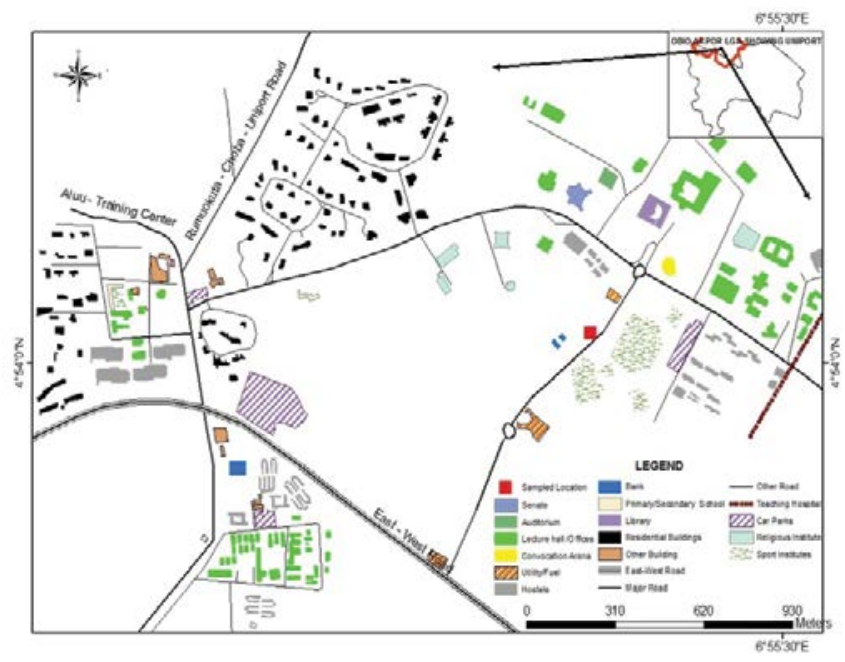

Figure 1: Map of University of Port Harcourt showing study site in red box. 
Citation: Babatunde BB, Kika PE, Ugoeze KC, Nwanchukwu N, Sikoki FD et al. (2016) Ecotoxicity Potentials of Residual Paracetamol and Personal Care Products (PPCPS) in Household Waste at the University of Port Harcourt, Nigeria. J Environ Anal Toxicol 5: 339. doi:10.4172/21610525.1000339

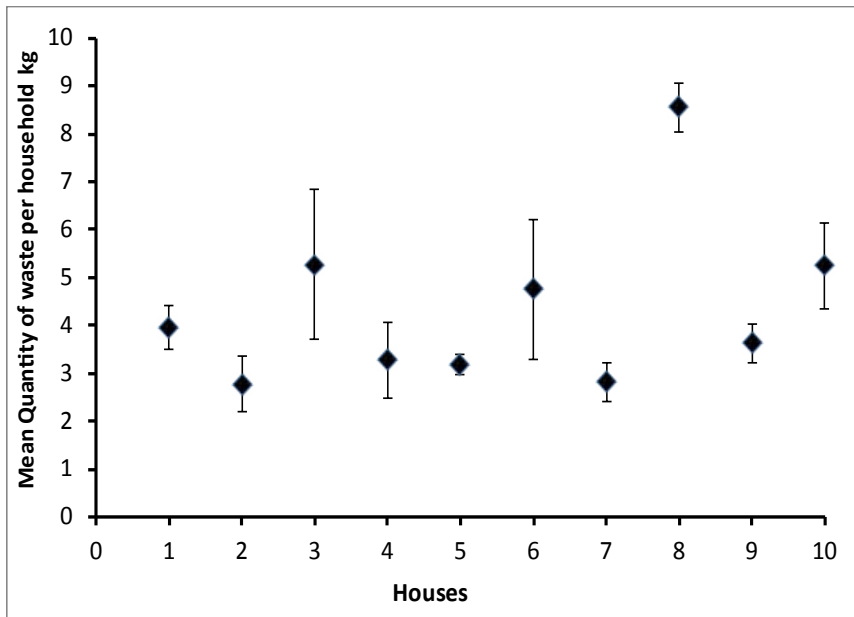

Figure 2: Quantity of Solid Waste generated in 10 selected households in the staff quarters (Gambia-Ama).

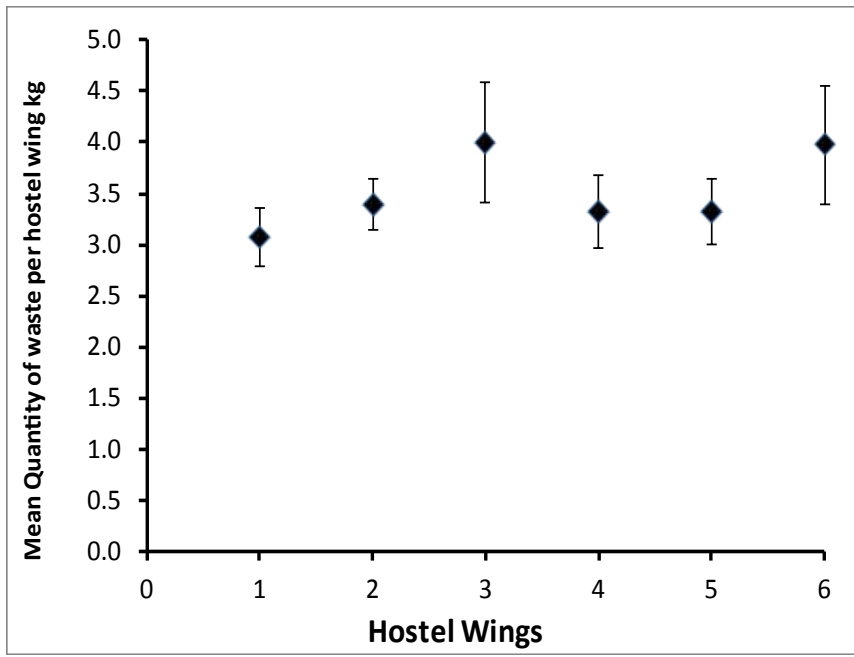

Figure 3: Quantity of Solid Waste generated in 6 wings of Block D, female students hostel at Delta Park.

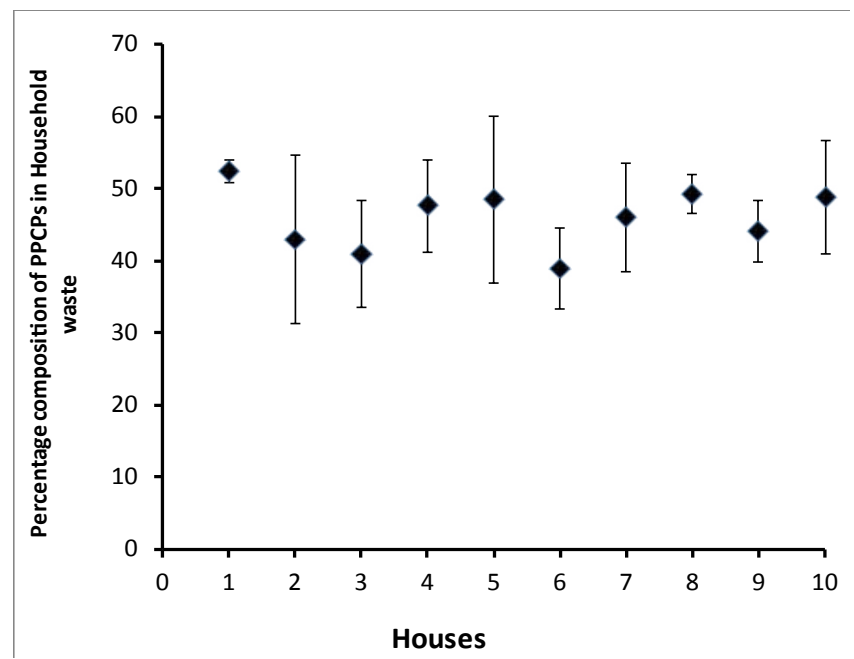

Figure 4: Relative amounts of Pharmaceuticals and Personal Care Products produced in Staff Quarters (Gambia-ama).

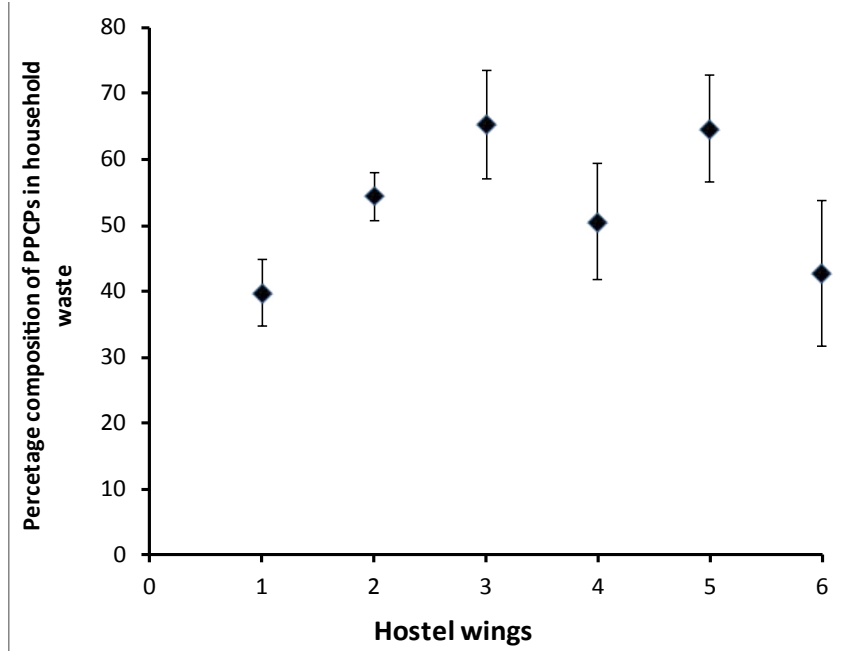

Figure 5: Relative amounts of Pharmaceuticals and Personal Care Products in students hostel (Delta Park, Block D).

\section{Residual concentration of paracetamol in waste}

The overall average residual concentration of Paracetamol in waste from staff quarters and student's hostel was $0.6702 \pm 0.006 \mathrm{mg} / \mathrm{kg}$ while that contained in staff quarters was $0.6569 \pm 0.002 \mathrm{mg} / \mathrm{kg}$ while the average concentration of the standard culture of Paracetamol was 0.386 $\pm 0.04 \mathrm{mg} / \mathrm{g}$. Individual concentrations of Paracetamol analysed from solid waste samples in the staff quarters and student hostel is provided in Figure 6. In the sudent hostel, average residual Paracetamol concentrations ranged from $0.579 \pm 0.003$ to $0.684 \pm 0.004 \mathrm{mg} / \mathrm{kg}$ with wing 3 and 2 recording the highest and lowest values respectively. While in the staff quarters samples, Paracetamol concentrations ranged from $0.577 \pm 0.002$ to $0.675 \pm 0.002$ with house 7 and 4 recording the highest and lowest values respectively.

\section{Discussion}

The present study showed that PPCPs were disposed off in household wastes. In the student's hostel, wing $\mathrm{C}$ had the highest mean percentage value of PPCPs in solid waste generated recording (65.29\%) and the least in wing A with $(39.69 \%)$. This simply means that the students in wing $\mathrm{C}$ used more of these products either as cosmetics or for health purposes than those in wing A. In the staff quarters, house 1 generated the highest amount with a percentage value of $52.26 \%$ while house 6 generated the least amount with $38.94 \%$ and this means that house 1 consumed more of these products than house 6 . The results showed that the student's hostel had a higher mean percentage of $52.92 \%$ compared to the staff quarters with a mean percentage value of $45.93 \%$. This can be explained using the age distribution between both locations. It was observed that the student's hostel (female) has more young people and all females than the staff quarters which is comprised mainly of the elderly ones and a combination of both sex. Females have higher consumption rates of these products especially as beauty care products (cosmetics and perfumes amongst others) and also single students who have the higher risk of unwanted pregnancy and infections thus will have more drugs consumption than the staff quarters which will have less use for cosmetics, pills for infections. It has been reported that between $50 \%$ to $90 \%$ of some drugs ingested is excreted as its active compound or as a conjugate metabolite into the toilets [13] or directly into water ways as practice in most poor Nations like Nigeria. 
Citation: Babatunde BB, Kika PE, Ugoeze KC, Nwanchukwu N, Sikoki FD et al. (2016) Ecotoxicity Potentials of Residual Paracetamol and Personal Care Products (PPCPS) in Household Waste at the University of Port Harcourt, Nigeria. J Environ Anal Toxicol 5: 339. doi:10.4172/21610525.1000339

Despite advice on pharmaceutical packaging that recommends the return of unused medicines to pharmacies, or occasionally to flush them down the toilet, the predominant method of disposal has been reported to be via household waste even in the developed countries like the United Kingdom [13] and United States of America [1]. The results obtained from the analysis of the paracetamol residue in household waste samples in students hostel sample sites was $0.6702 \pm$ $0.006 \mathrm{mg} / \mathrm{kg}$ and $0.6569 \pm 0.002 \mathrm{mg} / \mathrm{kg}$ for the staff quarters samples. These values were statistically significant at $\mathrm{P}<0.05$ when compared to $0.386 \pm 0.04 \mathrm{mg} / \mathrm{g}$ in the pure sample used to prepare the standard solution for the Beer Lambert curve. This means that the concentration of paracetamol residues found in the household waste generated in both study sites were higher than those found in the pure cultures. The implication of this result means, potent levels of Paracetamol analysed in the present study and possibly others such as antibiotics could enter into the environment when the household waste is finally disposed off in dumpsites and leach, contaminating surface and ground water as well as interfere with microbial communities in soils etc. There was no significant difference in concentrations of residual Paracetamol analysed in the samples from the student's hostel and staff quarters $(\mathrm{P}>0.05)$ Figure 6, although the student's hostel recorded more PPCPs in its solid waste stream. The Tukey's test also showed no significant difference in residual paracetamol between the student hostel wings or between the staff quarters houses.

A risk assessment and management process of household disposal of medicine is worthy of consideration to avoid environmental contaminations. Discarded pharmaceuticals are defined in the United Kingdom by the Controlled Waste Regulations 1992 Her Majesty's Stationery Office [17] as clinical waste and as such are controlled by the Special Waste Regulations 1996 [18]. According to this legislation, such waste may be disposed of in landfill sites designed to accommodate hazardous waste, or it may be incinerated. However, once dispensed to or purchased by a member of the public in developing countries such as Nigeria, any unwanted pharmaceutical products are classified as household waste, and their disposal is not subject to any controls. The effects of uncontrolled disposal of drugs into the environment can have far reaching consequences as though their levels may be seen as small, their continuous disposal on daily basis may confer a pseudopersistent nature on them [1]. Other issues include increase chemical toxicity when they interact with other environmental chemicals. Manufacturer packaging usually recommends disposal by returning to the pharmacist; however, disposal via the sink/toilet or in normal household waste is common. Pharmaceuticals in landfill sites are subject to biological degradation processes, but some may persist and even leach into surrounding groundwater and rivers $[11,19,20]$.

Results obtained from the present study agree with reports from other places. An investigation into the disposal habits of the American public found that only $1.4 \%$ of the people they surveyed returned unused medication to the pharmacy, whereas $54 \%$ threw them away and $35.4 \%$ disposed of them in the sink/toilet [21]. In United Kingdom, Ref. [13] reported that two-thirds of medications (63.2\%) were disposed off in household waste and household waste constitute an important pathway for the exit of PPCPs into the environment.

\section{Conclusion}

The present study showed clearly that household waste is an important pathway for disposal of PPCPs into the environment and indeed the active ingredient of these chemicals as shown by the paracetamol residue enter the environment through this pathway. The

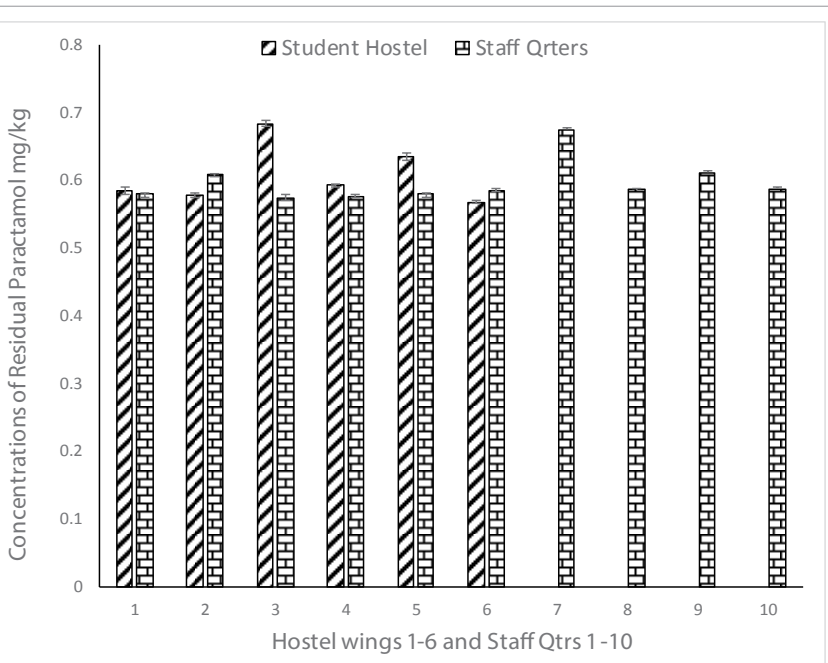

Figure 6: Concentration of residual Paracetamol in Student hostel and Staff quarters.

occurrence of PPCPs in the environment even at low levels has been reported to cause irreversible changes even at the genetic level. An alternative route of disposal of medicine and personal care products is advocated which may include return of medicine to producers for appropriate disposal in an integrated green pharmacy approach.

\section{References}

1. Daughton CG, Ternes TA (1999) Pharmaceuticals and personal care products in the environment: agents of subtle change? Environ Health Perspect 107 Suppl 6: 907-938.

2. Pfleger K, Maurer HH, Weber A (1999) Mass Spectral and GC Data of Drugs, Poisons, Pesticides, Pollutants and Their Metabolites. 2nd edn. 1999 Weinheim, Germany 1: 3

3. Aga DS, Thurman EM (2001) Formation and transport of the sulfonic acid metabolites of alachlor and metolachlor in soil. Environ Sci Technol 35: 24552460.

4. Rabølle M, Spliid NH (2000) Sorption and mobility of metronidazole, olaquindox, oxytetracycline and tylosin in soil. Chemosphere 40: 715-722.

5. Xia K, Bhandari A, Das K, Pillar G (2005) Occurrence and fate of pharmaceuticals and personal care products (PPCPs) in biosolids. J Environ Qual 34: 91-104.

6. Heberer T (2002) Occurrence, fate, and removal of pharmaceutical residues in the aquatic environment: a review of recent research data. Toxicol Lett 131 5-17.

7. Heberer T, Stan HJ (1997) Determination of clofibric acid and N-(phenylsufonyl)sarcosine in sewage, river and drinking water. International Journal of Environmental Analytical Chemistry 67: 113-124.

8. Kolpin DW, Furlong ET, Meyer MT, Thurman EM, Zaugg SD, et al. (2002) Response to comments on Pharmaceuticals, hormones, and other organic wastewater contaminants in US streams: a national reconnaissance. Environ Sci Technol 36: 1202-1211.

9. Haggard BE, Galloway JM, Green WR, Meyer MT (2006) Pharmaceuticals and other organic chemicals in selected north-central and northwestern Arkansas streams. J Environ Qual 35: 1078-1087.

10. Eckel WP, Ross B, Isensee RK (1993) Pentobarbitol found in ground water Groundwater 31: 801-804.

11. Holm JV, Rügge K, Bjerg PL, Christensen TH (1995) Occurrence and distribution of pharmaceutical organic compounds in the groundwater down gradient of a landfill (Grindsted, Denmark). Environ Sci Technol 29: 1415-1420.

12. Ahel M, Jelicic I (2001) Phenazone analgesics in soil and groundwate below a municipal solid waste landfill. In: Daughton CG, Jones-Lepp T (Eds) Pharmaceuticals and Personal Care Products in the environment: Scientific and Regulatory Issues. America Chemical Society, Washington DC, USA. pp $100-115$. 
Citation: Babatunde BB, Kika PE, Ugoeze KC, Nwanchukwu N, Sikoki FD et al. (2016) Ecotoxicity Potentials of Residual Paracetamol and Personal Care Products (PPCPS) in Household Waste at the University of Port Harcourt, Nigeria. J Environ Anal Toxicol 5: 339. doi:10.4172/2161 0525.1000339

13. Jonathan PB, Voulvoulis N (2005) Household disposal of Pharmaceuticals as Pathways for Aquatic contamination in the United Kingdom. Environ Health perspect 113: 1705-1711.

14. Giger W, Alder AC, Golet EM, Kohler EHP, McArdell CS, et al. (2003) Occurrence and fate of antibiotics as trace contaminants in wastewaters, sewage sludges and surface water. Chimia 57: 485-491.

15. Zwiener C, Glauner T, Frimmel FH (2000) Biodegration of pharmaceutical residues investigated by SPE-GC/ITD-MS and on-line derivatization. HRC-J High Res Chromagr 23: 474-478.

16. Daughton CG (2003) Pollution from combined activities, actions and behaviours of the public: Pharmaceuticals and Personal Care Products. NorCal SETAC News 2003 14: 5-15.
17. Her Majesty's Stationery Office (1992) The Controlled Waste Regulations, London.

18. Her Majesty's Stationery Office (1996) The Special Waste Regulations, London

19. Ahel M, Mikac N, Cosovic B, Prohic E, Soukup V (1998) The impact of contamination from a municipal solid waste landfill (Zagreb, Croatia) on underlying soil. Water Sci Technol 37: 203-210.

20. Schwarzbauer J, Heim S, Brinker S, Littke R (2002) Occurrence and alteration of organic contaminants in seepage and leakage water from a waste deposit landfill. Water Res 36: 2275-2287.

21. Kuspis DA, Krenzelok EP (1996) What happens to expired medications? A survey of community medication disposal. Vet Hum Toxicol 38: 48-49. 